\title{
Klippel-Trenaunay-Weber Syndrome
}

National Cancer Institute

\section{Source}

National Cancer Institute. Klippel-Trenaunay-Weber Syndrome. NCI Thesaurus. Code C84801.

A rare syndrome characterized by the presence of port-wine stain (a vascular malformation), varicose veins, and hypertrophy of the soft tissues and bones in an extremity. It usually affects one extremity, most commonly a leg. 